\title{
Evaluation of Classroom Teaching Effect Based on Facial Expression Recognition
}

\author{
Jun Mao* \\ School of Information Science and Engineering, Jiaxing University, Jiaxing 314001, China \\ *Corresponding author: Jun Mao, morejune@tom.com
}

\begin{abstract}
Classroom is an important environment for communication in teaching events. Therefore, both school and society should pay more attention to it. However, in the traditional teaching classroom, there is actually a relatively lack of communication and exchanges. Facial expression recognition is a branch of facial recognition technology with high precision. Even in large teaching scenes, it can capture the changes of students' facial expressions and analyze their concentration accurately. This paper expounds the concept of this technology, and studies the evaluation of classroom teaching effects based on facial expression recognition.
\end{abstract}

Keywords: Facial expression; Expression recognition; Classroom teaching; Effect evaluation

Publication date: December 2021; Online publication: December 23, 2021

\section{Introduction}

Classroom teaching effect is the key index to measure the operation level of school and teachers' teaching ability of most schools. However, based on the current evaluation of classroom teaching quality, the methods and systems of schools in various regions are different. This situation is relatively unfavorable for unified management. The traditional way of classroom teaching evaluation involves manual recording and after-school investigation. This kind of analysis is not comprehensive and requires a lot of manpower, which is of little significance to the improvement of classroom teaching effect.

\section{Facial expression recognition technology}

\subsection{Facial recognition}

Face detection technology is the premise of facial expression recognition ${ }^{[1]}$. From the field classification of this technology, facial recognition technology actually belongs to the special function of computer target detection, and the difference between general target detection is very obvious. In short, facial recognition technology is very special; for example, the facial details of people are very complex, and the differences between individuals are obvious. At the same time, in class, students' faces are usually blocked by bangs or fringe, masks, books and other items, which are the source of difficult facial recognition ${ }^{[2]}$. The specific working steps are shown in Table $\mathbf{1 .}$

\subsection{Facial expression recognition}

Expression actually refers to separation of a specific expression state from dynamic or static images, and finally analysis of the psychological emotion of the processed object ${ }^{[3]}$. Conventional expression recognition can be divided into three steps: face image acquisition, expression feature extraction, as well as expression classification and emotion scoring. 
Table 1. The steps of facial recognition technology

\begin{tabular}{|c|c|}
\hline Step name & Details \\
\hline $\begin{array}{l}\text { Data set and image } \\
\text { preprocessing }\end{array}$ & $\begin{array}{l}\text { In order to ensure the application effect of facial recognition technology, users usually carry out } \\
\text { corresponding preprocessing, such as color transformation, random cutting and size transformation. }\end{array}$ \\
\hline Face location & $\begin{array}{l}\text { If you want to recognize facial expressions or implement face detection, you need to locate the position } \\
\text { of the face first, that is, traverse the image with a small window of the specified size, get several } \\
\text { windows, and analyze whether there are faces in each window. This is the preliminary face location } \\
\text { step. However, there may be multiple faces in a picture, so it is difficult to meet the requirements for } \\
\text { windows of the same size, and thus, the size needs to be adjusted. At present, the method used is to keep } \\
\text { the window size stable and to scale the original image for many times to form an image pyramid, as } \\
\text { shown in Figure 1. }\end{array}$ \\
\hline Border regression & $\begin{array}{l}\text { The window containing face obtained in the face location link will be compared with the label of the } \\
\text { original image, and then the standard threshold will be set artificially. If the comparison result is greater } \\
\text { than the threshold, it can be used as an alternative window. }\end{array}$ \\
\hline
\end{tabular}

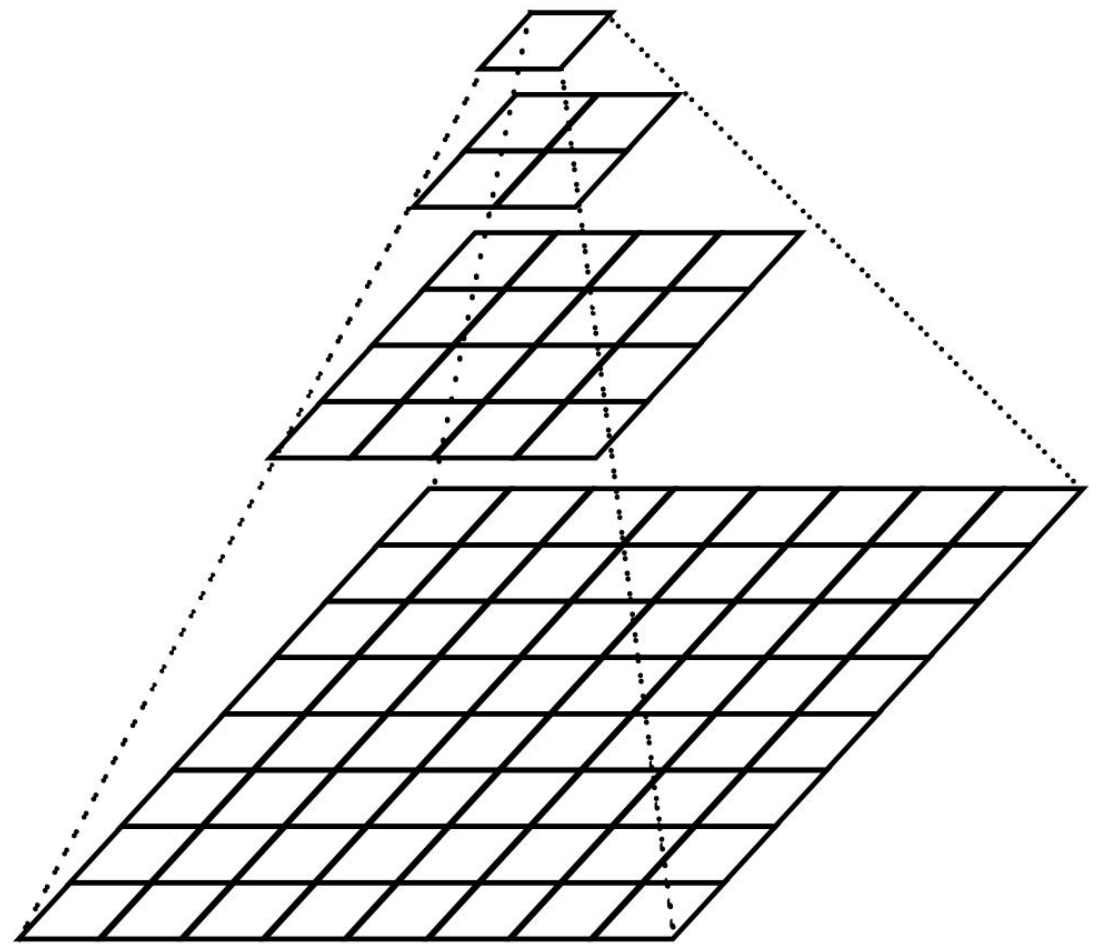

Figure 1. Image pyramid

\section{Application of facial expression recognition technology}

\subsection{Facial recognition}

Facial recognition is the foundation of facial expression recognition technology. After testing the facial recognition effect of several open-source software in the teaching scene, a technician found that the data display effect is not good. Therefore, technicians optimized the entire facial recognition process, which is divided into three stages. In the first stage, CNN1 network is used to quickly obtain the initial candidate window and its bounding box regression vector. The second stage is to send all candidate boxes to the more complex CNN2 analysis, screen out a smaller number of accurate candidate boxes, and use border regression again to calibrate those boundaries. The work of the third stage is very similar to that of the 
second stage, but a deeper convolution network structure will be used in the third stage. The specific three stages are shown in Figure 2.

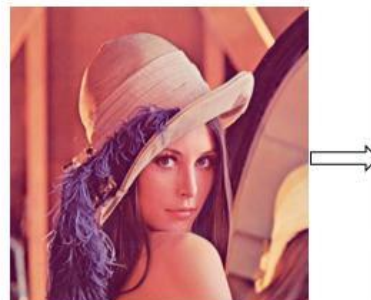

Original image

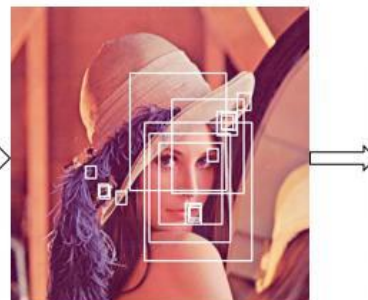

CNN1

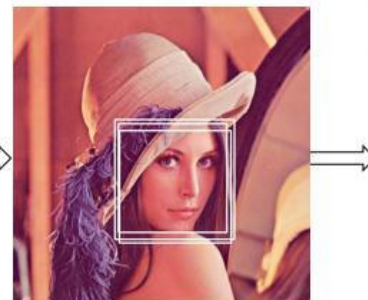

CNN2

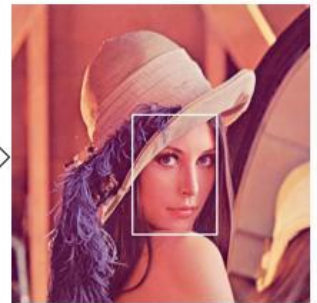

CNN3

Figure 2. Three stages of face detection

\subsection{Facial expression recognition}

After the end of face detection, it is necessary to carry out expression recognition and scoring for the detected faces, which is also laying the foundation for the implementation of classroom effect analysis. In the implementation stage of this part of the work, technicians should pay attention to the application of technology in the classroom, and redefine the common expressions in the classroom.

\subsubsection{Facial expression redefinition}

As an objective index of human emotion, facial expression belongs to common explicit behavior. Facial expression itself can be measured and observed. The direction of measurement is the muscle movement mode of facial expression. In the Microsoft system commonly used in schools, its expression recognition function can define several basic expressions such as anger, contempt, surprise and disgust, and can also analyze other representative expression contents, but it needs to realize network interception. These facial expressions are relatively rare in the normal classroom teaching environment, so it is necessary to redefine facial expressions for the special classroom environment. At present, the five expressions commonly used in the classroom are listening, doubt, understanding, resistance and disdain. These expressions are the result of redefining according to the students' psychological state, and their divisions are shown in Figure 3.

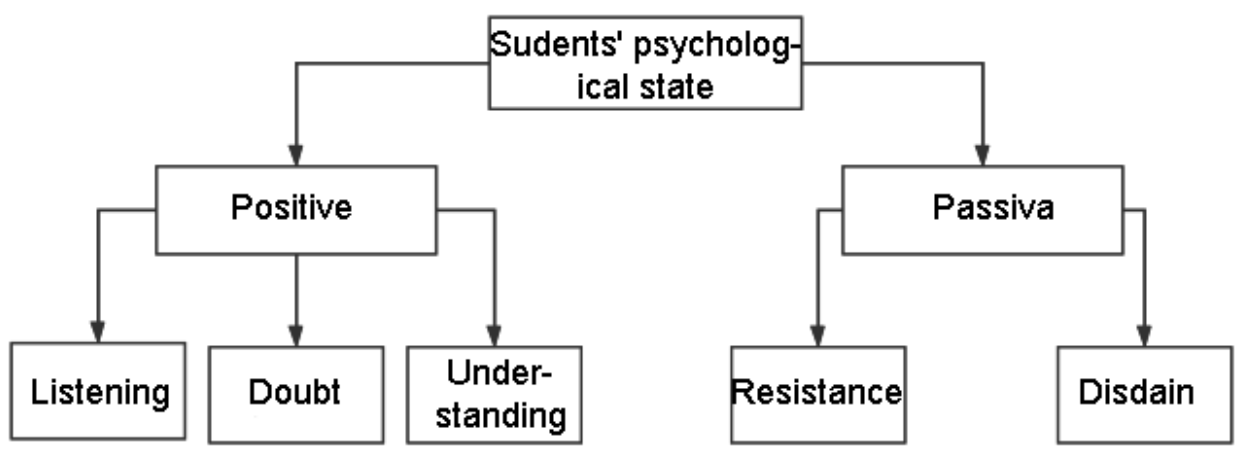

Figure 3. Five expressions redefined according to students' psychological state

Listening means that students are listening carefully, doubt means that students are actively thinking about problems, understanding means that students are accepting the content, resistance means that students do not accept the teaching content, and disdain means that students are not interested in the teaching content. 
After observing the facial expression characteristics of students in the classroom, a technician summarized the facial features according to the above-mentioned five expressions, as shown in Table 2.

Table 2. Facial features corresponding to five expressions

\begin{tabular}{|c|c|c|c|}
\hline $\begin{array}{l}\text { Psychological } \\
\text { states }\end{array}$ & Head features & Ocular features & $\begin{array}{c}\text { Labial ministry } \\
\text { features }\end{array}$ \\
\hline Listening & $\begin{array}{l}\text { Look up or directly with the head } \\
\text { angle changes between } 0-60^{\circ}\end{array}$ & $\begin{array}{l}\text { The eyebrows stretch naturally, and the angle } \\
\text { between the two ends of the eyebrows and the } \\
\text { middle of the eyes is less than or equal to } 120^{\circ}\end{array}$ & $\begin{array}{l}\text { The feature is not } \\
\text { obvious }\end{array}$ \\
\hline Dout & $\begin{array}{l}\text { Slightly tilt or lower the head, } \\
\text { and the head angle changes } \\
\text { between } 0-60^{\circ}\end{array}$ & $\begin{array}{l}\text { The eyebrows are tightly furrowed, and the angle } \\
\text { between the two ends of the eyebrows and the } \\
\text { middle of the eyes is more than } 120^{\circ}\end{array}$ & $\begin{array}{l}\text { The corners of the } \\
\text { mouth move } \\
\text { downwards }\end{array}$ \\
\hline Understanding & $\begin{array}{l}\text { Tilt the head up or lower the } \\
\text { head, and the head angle changes } \\
\text { between } 0-60^{\circ}\end{array}$ & The brows stretch naturally & $\begin{array}{l}\text { The corners of the } \\
\text { mouth rise }\end{array}$ \\
\hline Resistance & $\begin{array}{l}\text { Lower or turn the head, and the } \\
\text { head angle changes for o more } \\
\text { than } 60^{\circ}\end{array}$ & The feature is not obvious & $\begin{array}{l}\text { The feature is not } \\
\text { obvious }\end{array}$ \\
\hline Disdain & $\begin{array}{l}\text { Lower or turn the head, and the } \\
\text { head angle changes for more } \\
\text { than } 60^{\circ}\end{array}$ & The feature is not obvious & $\begin{array}{l}\text { One side of the } \\
\text { mouth moves up }\end{array}$ \\
\hline
\end{tabular}

\subsubsection{Facial feature extraction}

In order to accurately extract the facial expression features of the face, it is necessary to detect the key feature points on the face. These feature points will display the face shape and irrelevant contour. The face shape and nose contour have no obvious correlation with the expression, so they need to be removed.

\section{Evaluation of classroom teaching effect based on facial expression recognition 4.1. Calculation of head up rate}

In the teaching classroom, the face detection of students needs to be carried out every once in a while, and the changes of each detection should be recorded. Finally, the head up rate of students in the classroom can be obtained through statistics, which can be used as the key basis for analyzing students' concentration in class.

\subsubsection{Head up rate of individual student}

The head up rate of students in class can help teachers master the actual listening state of each student. Therefore, face detection is carried out at set intervals and the detected contents are numbered. However, the total number of faces detected each time may be different. Therefore, the same number cannot represent a specific student. In the calculation of head up rate based on face detection, the difficulty is personal positioning. In the classroom teaching environment, the positions of individual student and shooting equipment are relatively fixed, so the face detected at the same position at different times can be regarded as a person.

\subsubsection{Overall head up rate of the entire class}

The calculation of the overall head up rate of the entire class refers to the proportion of the head up rate of 
the whole class in the total number of students within a certain time interval, which is also a reflection of the overall listening state of students in the classroom. In short, it is used to calculate the number of faces detected each time, then calculate its proportion in the total number, and finally calculate the average head up rate of the entire class.

\subsubsection{Analysis of student focus}

After calculating the head up rate of individual students and the entire class, technicians can analyze the students' concentration in the classroom to a certain extent. After many experimental analyses, they can sum up experience from a pool of data.

In general classes, if the overall head up rate of students is less than $50 \%$, it means that the overall concentration is poor; if it is between $50 \%-70 \%$, it means that the concentration is good; if the overall head up rate is more than $70 \%$, it means that the overall concentration of students is high.

From the perspective of students, in addition to analyzing their head up rate in the whole class, we also need to pay attention to the fit between their head up behavior and the overall behavior of the whole class at each time node. This analysis direction is mainly aimed at students' personal focus. For example, in a certain period of time, when a student is always in the state of lowering his head while the overall head up rate of the class is more than $70 \%$, it can be interpreted that the student is not focused enough in this period of time. But if the head up rate of the class is less than $50 \%$ during this time period, it can be interpreted that the student's concentration is very high ${ }^{[4]}$.

\subsection{Emotion score calculation}

After the implementation of face detection work, technicians can input the detected content into the feature engineering for analysis. Under normal circumstances, the scores of listening, doubt and understanding are 7, 8 and 9, respectively, while the scores of disdain and resistance are usually about - 10. Obviously, the higher the score, the higher the students' degree of concentration, and this emotional score is compared with the overall level of the entire class. Therefore, if the score is more than 0.5 , it indicates that their performance in the classroom is higher than the overall average level. Finally, the technicians can obtain the emotional score of students in the whole class by calculating the average value of students' score, which can be used as the basis for judging the quality of classroom teaching.

\section{Conclusion}

In conclusion, the development prospect of the evaluation of classroom teaching effect based on facial expression recognition is very good. At present, there is a way to compute students' head up rate in the classroom based on facial expression recognition technology. This has a very obvious impact on students' emotion scoring, concentration analysis and the improvement of classroom teaching effect. In the followup investigation, it is necessary to continue to optimize the application of this kind of technology in combination with Jiaxing University's actual situation and find appropriate ways to improve the teaching effect according to the analysis results.

\section{Funding}

This study was supported by Doctoral Foundation of Jiaxing University (cd70519047).

\section{Disclosure statement}

The author declares that there is no conflict of interest. 


\section{References}

[1] Liao E, Li W, Cai X, 2020, Research on Big Data Analysis and Teaching Decision of Visual Behavior Recognition. Engineering and Technological Research, 5(12): 233-235.

[2] Chen Z, Zhu X, 2019, Automatic Recognition of Learners' Emotions Based on Facial Expressions: Relevance, Status, Existing Problems and Improvement Path. Journal of Distance Education, 37(04): 64-72.

[3] Chen S, Dai J, Gao X, et al., 2019, Research on Dynamic Emotion Recognition of Students in Classroom Teaching. The Chinese Journal of ICT in Education, 2019(13): 33-36.

[4] He X, Gao Q, Li Y, et al., 2019, Research on Spontaneous Learning Facial Expression Recognition Based on Deep Learning Model. Computer Applications and Software, 36 (03): 180-186. 